\title{
Correction: Non-invasive measurement of sclerosis in cutaneous cGVHD patients with the handheld device Myoton: a cross-sectional study
}

\author{
Fuyao Chen · Laura E. Dellalana · Jocelyn S. Gandelman • Arved Vain • Madan H. Jagasia - Eric R. Tkaczyk
}

Published online: 17 January 2020

(c) Springer Nature Limited 2020

\section{Correction to: Bone Marrow Transplantation}

https://doi.org/10.1038/s41409-018-0346-7
In the original publication of this Correspondence, the $y$ axis was missing from Fig. 1a. The corrected figure is included in the HTML format and included with this correction.

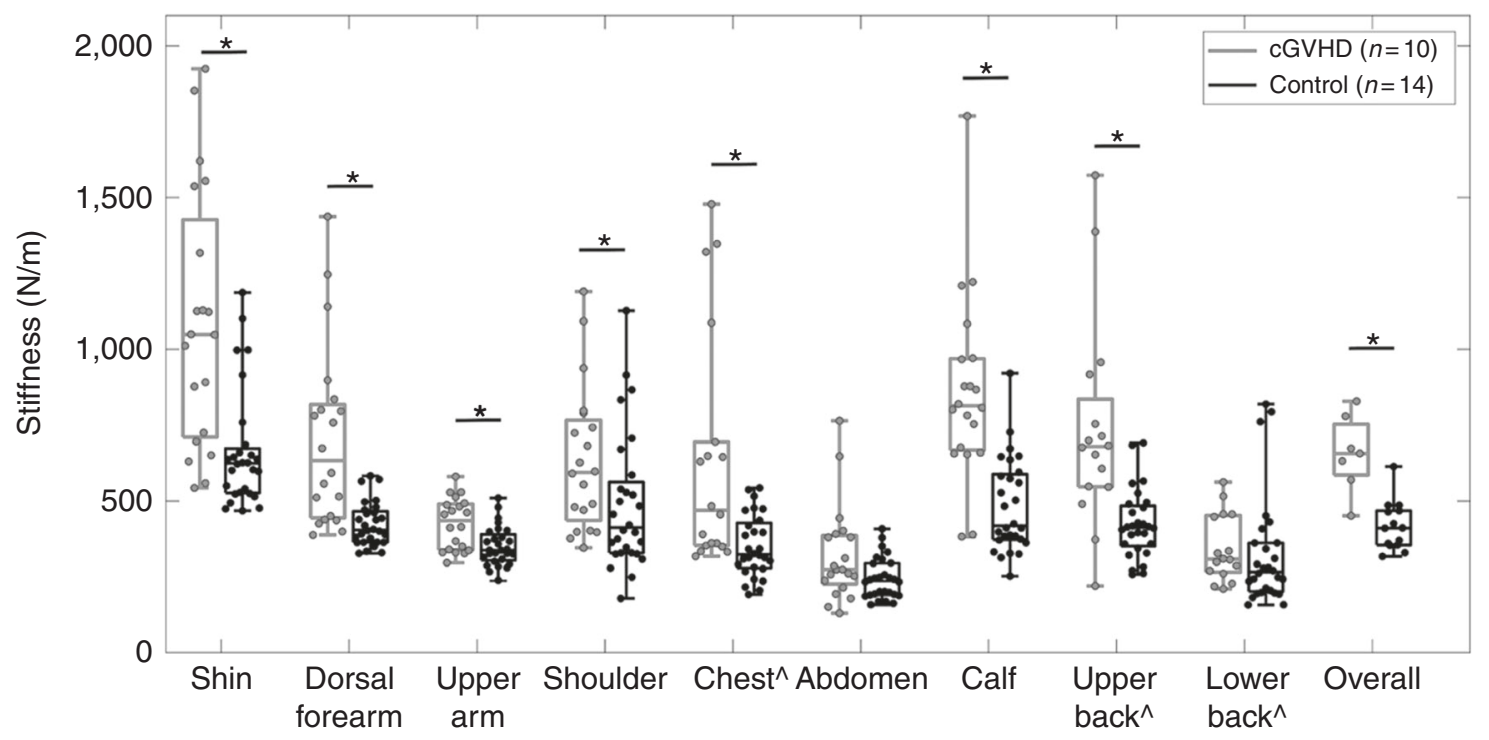

Fig. 1a 